\title{
Preparing a Family Communication Plan for Terrorist Attacks ${ }^{1}$
}

\author{
Rose Barnett ${ }^{2}$
}

\section{Preparing a Family Communication Plan for Terrorist Attacks}

The threat of terrorist attacks may be a new reality for your family; however, preparing a Family Communication Plan in the case of such an attack (no matter the particular type of attack) may be more similar to preparing for other emergencies than you might think. For example, if there were an emergency such as a natural disaster that required all family members knowing how to get in touch with one another in order to evacuate, the steps would be very similar to that of this Family Communication Plan for Terrorist Attacks. Because of the unique nature of some of the potential hazards, however, this plan will help you think about communication in a new terrorism-based context that will guide you to efficiently and effectively establish your plan.

Good family communication requires some degree of advanced preparation, basic steps and logical thinking. This section will outline some decisions you will need to make as well as some specific action steps for you to discuss with your family. It will also provide a format for you to use as an outline for your own individualized Family Communication Plan that will be tailor made for your family in case of need.

\section{Individual Family Roles}

1. Consider the structure of your family. Do you have a traditional family structure with two parents, or are you a single parent? Is one of the parents out of town or are both here? Do you have extended family members that need to be included in your plan? Do you have pets that are considered family members? Describe your family below and list all family members. During your plan, each family member will be identified by his or her descriptor. (This will be used in a diagram that will display the steps for the Family Communication Plan in a diagram.)
Parent $1(\mathrm{P} 1)$ :
Parent 2 (P2):
Child 1 (C1):
Child 2 (C2):
Child 3 (C3):
Child 4 (C4):

\footnotetext{
1. This document is FCS9201, one of a series of the Department of Family, Youth and Community Sciences, Florida Cooperative Extension Service, IFAS, University of Florida, Gainesville FL 32611: First published: May 2003. Reviewed: May 2003. Reviewed by: Elizabeth Bolton, Ph.D., professor, Department of Family, Youth and Community Sciences. Please visit the EDIS Web site at http://edis.ifas.ufl.edu
}

2. Rose Barnett, Ph.D., assistant professor, Department of Family, Youth and Community Sciences, University of Florida, Gainesville FL 32611. 
Other:

Extended Family 1 (EF1):

Extended Family 2 (EF2):

Extended Family 3 (EF3):

Extended Family 4 (EF4):

Pet $1(\mathrm{P} 1)$ :

Pet $2(\mathrm{P} 2)$ :

Pet 3 (P3):

Pet 4 (P4):

2. Select a family member to be the Lead Contact for your family. This should be the primary parent with the most stable schedule and least amount of out-of-town travel. It should also be the parent that can keep the calmest in times of emergency. This Lead Contact will be the coordinator and will work through the next few steps for and with the family members.

\section{Lead Contact:}

3. Select a secondary Lead Contact in case the primary Lead Contact is detained for any reason. This will be the backup and should be the second most reliable family member. They should be as informed and familiar with the Family Communication Plan as the Lead Contact and be given all relevant information for safekeeping.

Secondary Contact:

4. Identify individual family roles in preparation for and in case of an attack. Determine who will perform the following duties on behalf of the entire family:

a. Prepare a Contact Card for Each Family Member. This includes information such as daily schedule, including locations throughout the day, general directions to each location, phone numbers, pager numbers, cell phone numbers, social security numbers, and blood type. Since these cards must be in the possession of the Lead Contact on a daily basis, it is ideal if they collect the information required for the cards from each member and complete the cards. A second set of cards should be given to the second Lead Contact in case the primary Lead Contact loses them or is detained. (Complete Contact Cards).

\section{Contact Card Completer:}

b. Monitor the threat condition. This requires a family member with access to information throughout the day, including the risk, type and extent of an attack. Ideally, the Lead Contact will be able to perform this duty, however, if another family member has more access to threat condition communications, they must be able to contact the Lead Contact immediately to inform them of the threat status and conditions. The Lead Contact will then determine if and when family members must be alerted as a result of a threat. If so, they will be responsible for coordinating this information by the means available at that time.

Threat Monitor: 
c. Identify a meeting place or meeting plan. The meeting place, if central, should be identified as a convenient place for all family members to convene. This may be the home or another familiar place easily accessible by all. Each family member must know the location of this meeting place in case they are separated from family and are arriving Meeting Place: independently.

d. Prepare and explain a Meeting Plan. The Lead Contact is responsible for ensuring that all family members arrive at the meeting place safely. This may require picking up family members that are not able to drive, such as children at schools, and ensuring that everyone is accounted for. The Lead Contact should call a family meeting to create a meeting plan. This will include basic information such as the family goal for the approximate time span involved in arriving at the meeting place from the time of the notice of threat, as well as the plan for transportation of all family members to the meeting place. All designated drivers must be identified in this plan with a list of which family members they are responsible for, as well as the order in which they will pick them up and all appropriate information required to do so. The plan should include
arrangements for pets. (Create a diagram of the meeting plan using information in \#1.) them up and all appropriate information required to do so. The plan should include
arrangements for pets. (Create a diagram of the meeting plan using information in \#1.)

\section{Meeting Plan:}

e. Make arrangements to contact Extended Family members. Extended family members may be in the immediate area or in other locations. Whether they need to be part of the meeting plan, or simply contacted to alert that the family is preparing for a threat, the extended family must know of the immediate family's whereabouts and plan of action. This will provide another backup resource in time of need with the information necessary to account for all other family members.

f. Devise a plan to let neighbors know where you will be and how to contact you. Another source of backup are your neighbors. Identify the neighbor closest to you (not necessarily in proximity but one that you feel you can depend on) and exchange family communication plans. This will allow each family member with yet another source of contact and transportation should a real threat occur. Make sure that each family member has this external Neighbor Contact's name, address, phone number(s) and location(s) for a typical daily schedule, both during the week and weekend. Having another contact will provide a safety net for both families and provide greater communication on the home front. A working Lead Contact may choose to select a Neighbor Contact that is at home during the day should they wish to collect information regarding the feasibility of returning family members to the home or meeting there if that is the designated meeting place.

Neighbor Contact:

Neighbor Address(es):

Phone(s): 